\title{
Solitary Cutaneous Metastasis of Carcinoma Larynx - An Unusual Occurrence
}

\author{
Jyoti Tele ${ }^{1}$, S.R. Kanetkar ${ }^{2}$, S.S. Kumbhar ${ }^{3}$, Aaliya. S $^{4}$, Parneet Kaur ${ }^{5}$ \\ ${ }^{1}$ Assistant Professor, ${ }^{2}$ Professor and Head, ${ }^{3}$ Associate Professor, ${ }^{4,5}$ Tutor, \\ Krishna Institute of Medical Sciences, Deemed to be University, Karad, Maharashtra, India.
}

Corresponding Author: Sujata R. Kanetkar

DOI: https://doi.org/10.52403/ijhsr.20220227

\begin{abstract}
Background - Carcinoma larynx with cutaneous metastasis is rare to occur. Cutaneous metastasis from head and neck region are usually considered a poor prognostic sign.

Case Report - We report a case of moderately differentiated carcinoma of larynx presenting with solitary cutaneous metastasis in suprascapular region. Patient is a 40 year old lady, farmer by occupation who developed dysphagia and throat pain for which she was investigated and on biopsy was diagnosed as moderately differentiated squamous cell carcinoma of larynx. When she was admitted for chemoradiotherapy, a swelling was noted in right suprascapular region. FNAC of this swelling revealed metastatic Squamous Cell Carcinoma.

Conclusion - Cutaneous metastases are believed to be due to systemic spread and they represent terminal stage of malignant disease with limited survival period. FNAC is a minimally invasive method, that can be used to diagnose such lesions and it is a good alternative to performing biopsies.
\end{abstract}

Keywords: Carcinoma Larynx, Solitary Cutaneous Metastasis, Squamous Cell Carcinoma of head and neck

\section{INTRODUCTION}

Cutaneous metastasis is a rare entity itself, representing $<10 \%$ of all distant metastasis. ${ }^{1}$ In Squamous Cell Carcinomas of head and neck, cutaneous metastasis has been reported in only $1-2 \%$ of patients. ${ }^{2}$ And whenever they occur, are considered as poor prognostic sign. Hypo and oropharyngeal malignancies constitute about $1.1 \%$ of all malignancies in the world and $3.8 \%$ of all malignancies in India. ${ }^{3}$ At least $50 \%$ of patience have positive cervical lymph nodes at the time of diagnosis. Treatment offered is either radical chemoradiation, palliative radiation or chemotherapy which depends on stage of disease and generalised health status of the patient. Presence of cutaneous metastasis at the time of presentation indicates advanced stage of the disease and its diagnosis on fine needle aspiration cytology (FNAC) becomes crucial in patient management.

\section{CASE REPORT}

A 40 year old lady, farmer by occupation presented to ENT OPD with progressive dysphagia and throat pain since one month.

CT Neck revealed circumferential symmetrical wall thickening of hypopharynx extending to cervical and upper thoracic oesophagus causing significant luminal narrowing at $\mathrm{C} 4$ level and posterior indentation of trachea and loss of fat planes suggesting malignant neoplastic etiology. Biopsy from the growth showed features of moderately differentiated Squamous Cell Carcinoma. At the time of clinical examination, a swelling was noted in right suprascapular region 
(Refer image ' 1 ') measuring $2 \times 1.5 \mathrm{~cm}$ in size, which patient was ignoring since a month. The fine needle aspiration cytology was performed under USG guidance and it showed features of metastatic deposit of Squamous Cell Carcinoma. The swelling measured $13 \times 21 \mathrm{~mm}$ on ultrasonography, and was well defined hypoechoic in nature. On ultrasound, the lesion appeared in the muscular plane with central anechoic area. (Refer image '2')

On aspirating the lesion, $1 \mathrm{ml}$ pale clear fluid with hemorrhagic tinge came out and smears were prepared from that. $H \& E$ and Giemsa stains were used for staining the slides. Microscopically, loosely scattered neoplastic squamous cells, as well as at places arranged in small cohesive clusters were seen. (Refer image ' 3 ') The neoplastic squamous cells appeared large, round to polygonal with enlarged hyperchromatic nuclei and moderate to ample amount of dense eosinophilic keratinised cytoplasm.(Refer image '4', '5' and ' 6 ') Few binucleate and multinucleate giant cells were also noted.(Refer image '7') Background revealed necrotic debris, few scattered inflammatory cells and numerous RBCs. Diagnosis of metastasis of Squamous Cell Carcinoma with necrosis was rendered in view of history of the patient.

The patient was started with chemoradiotherapy and till further follow up. Patient was tolerating chemotherapy well.

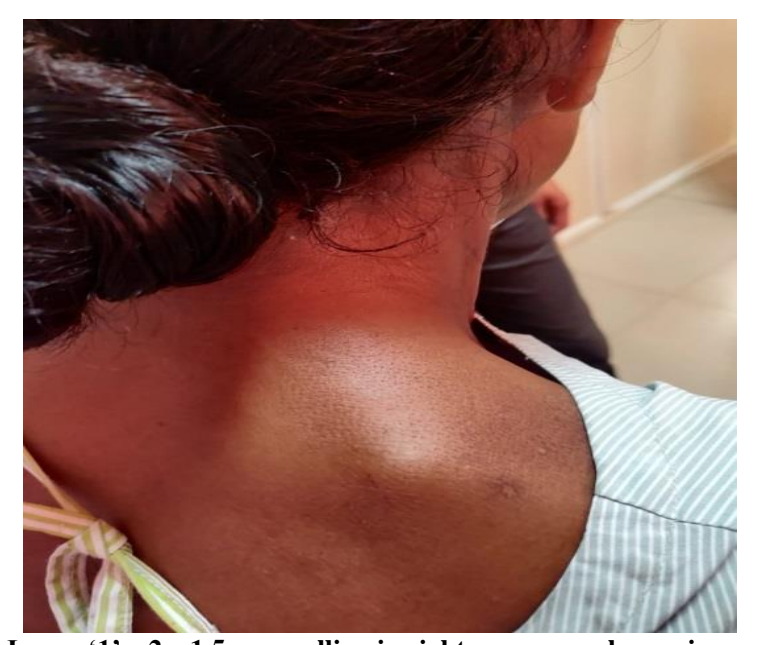

Image ' 1 ' $-2 \times 1.5 \mathrm{~cm}$ swelling in right suprascapular region.

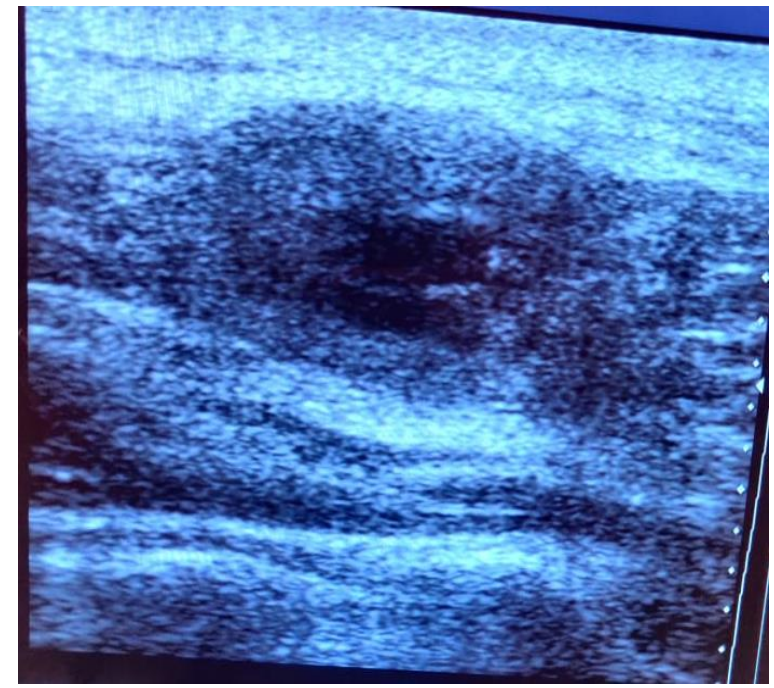

Image ' 2 ' - USG showing hypoechoic lesion with central anechoic area.

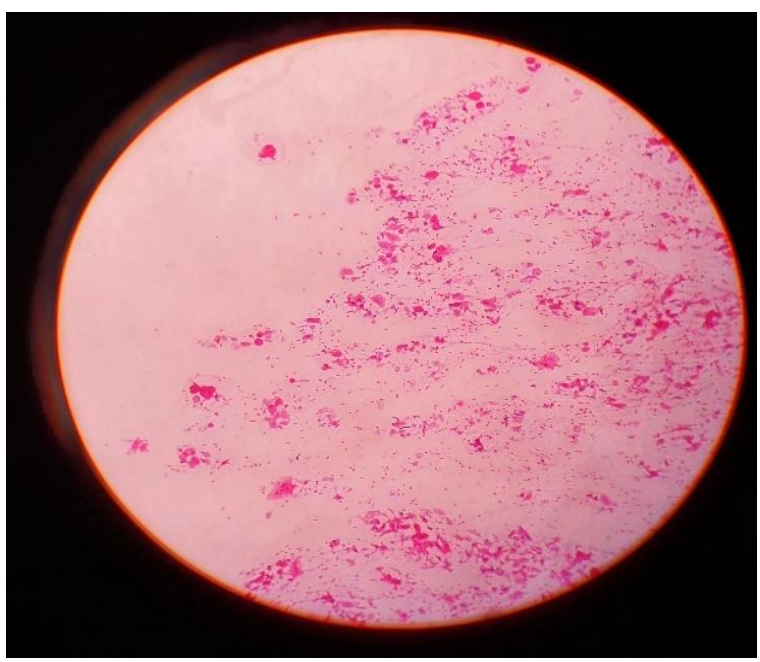

Image ' 3 ' - (40x magnification) showing small clusters and many scattered neoplastic squamous cells.

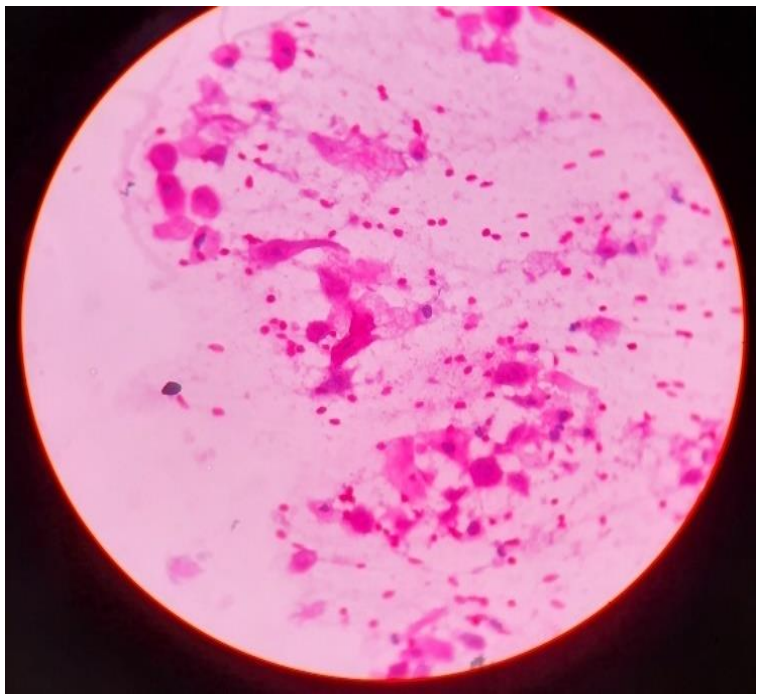

Image '4' - (100x magnification) showing round to polygonal cells with hyperchromatic nuclei. 


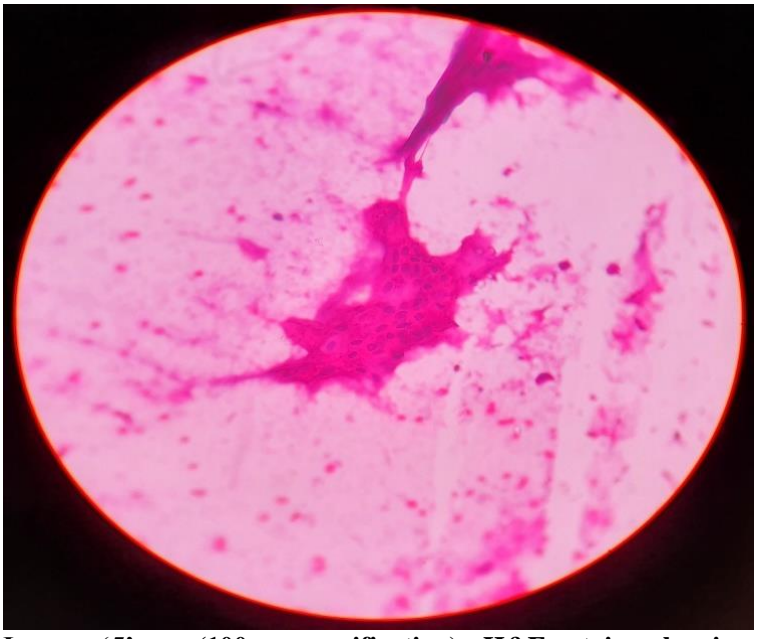

Image '5' - (100x magnification) $\mathrm{H} \& \mathrm{E}$ stain showing neoplastic squamous cells in clusters with keratinised cytoplasm.

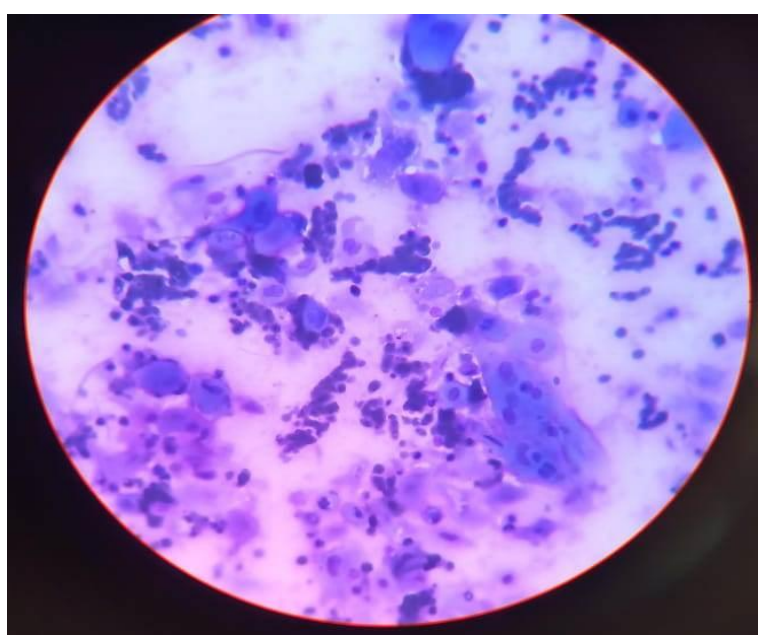

Image ' 6 ' - (400x magnification) On Giemsa stain showing clusters of neoplastic squamous cells having keratinised cytoplasm.

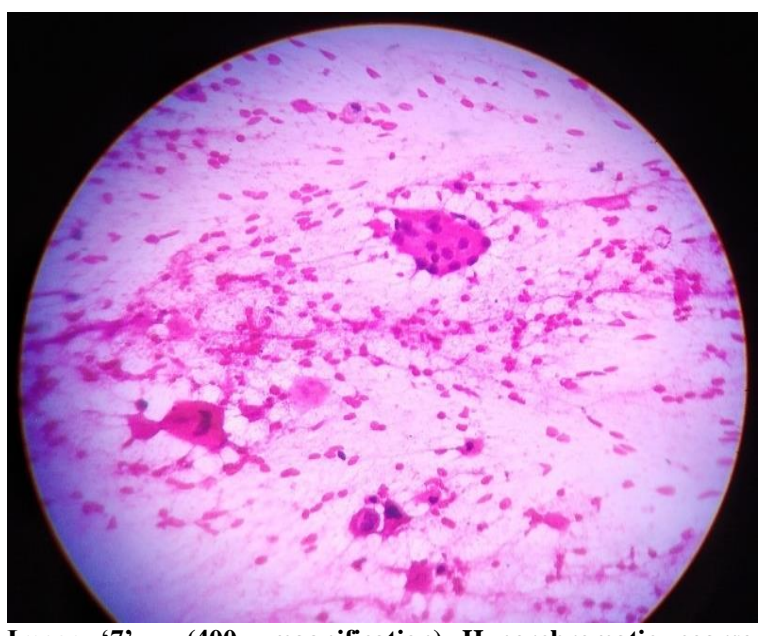

Image ' 7 ' - (400x magnification) Hyperchromatic coarse nuclei of neoplastic squamous cells and multinucleate giant cells.

\section{DISCUSSION}

Cutaneous metastasis is considered as a grave prognostic sign in any malignancy. ${ }^{4,5}$ Development of cutaneous metastasis may indicate recurrence, failure of ongoing therapeutics or rarely it may be the first sign of unsuspected malignant tumor. ${ }^{6}$ Squamous Cell Carcinomas are responsible for $95 \%$ of laryngeal carcinomas in adults and is the commonest tumor of upper respiratory tract. Usually distant metastases occur to lungs ( 70$75 \%)$, liver (17-38\%) and bone (23-44\%). ${ }^{7}$ Cutaneous metastasis from laryngeal carcinomas is rare and when they occur, are usually located on the neck, chest, scalp, face, arms and fingers. ${ }^{8}$ Most often cutaneous metastases affect the supradiaphragmatic area i.e. head, neck, thorax or upper extremities and infradiaphragmatic cutaneous metastases in laryngeal squamous carcinomas are exceptional. ${ }^{9}$ Our patient had a right suprascapular region cutaneous deposit. The exact mechanism of cutaneous metastasis in laryngeal carcinomas is not completely understood. The possible mechanisms are either direct spread or lymphatic spread or hematogenous spread. Spread through dermal lymphatics can result in development of cutaneous metastases. The hematogenous spread through pulmonary circulation or through azygous and vertebral venous plexus can occur.

Nodular, inflammatory, bullous, telangiectatic are various clinical forms of presentation of cutaneous metastasis. 11,12,13,14 Cutaneous metastases are usually multiple and rarely solitary, as was seen in our case. ${ }^{15}$ Diagnosis is based on biopsy most of the time. However, non-invasive procedure of fine needle aspiration cytology can distinguish metastatic deposits from other skin lesions and aid in diagnosis. ${ }^{16,17}$ We decided to take help of ultrasound guidance during FNAC procedure. The lesion was anechoic in the centre, suggesting a cystic nature of the lesion. Hence, to avoid risk of needle not hitting the solid part of the lesion, we used USG guidance.

Cutaneous metastases are associated with limited survival period. ${ }^{18}$ Rarely, they 
can be the first sign of an unknown malignancy. ${ }^{15}$ In our case, at the time of presentation only the cutaneous metastasis was diagnosed. There was no evidence of visceral metastases in our case. Treatment and prognosis depend on type and stage of the primary tumor. Cutaneous metastases are usually associated with poor prognosis. Our patient is planned for chemoradiotherapy. Initially chemotherapy is started with cisplatin to enhance the effect of radiotherapy. Also feeding jejunostomy was performed in view of severe dysphagia. An early diagnosis of cutaneous metastasis can help greatly in reducing morbidity and mortality. ${ }^{19}$

\section{CONCLUSION}

Solitary Cutaneous metastasis from primary laryngeal carcinoma is a rare presentation and is associated with poor prognosis.

The clinical polymorphism of cutaneous metastasis raises numerous problems of clinical diagnosis, leading to significant delays in diagnosis and initiation of treatment. Cytological study is cheap, cost effective and can be a useful substitute for other costly or invasive procedures.

\section{Acknowledgement: None}

\section{Conflict of Interest: None}

\section{Source of Funding: None}

\section{REFERENCES}

1. Brenner S, Tamir E, Maharshak N, Shapira J. Cutaneous manifestations of internal malignancies. ClinDermatol2001;19:290-7.

2. Shingaki S, Suzuki I, Kobayashi T, Nakajima T. Predicting factors for distant metastases in head and neck carcinomas: An analysis of 103 patients with locoregional control. J Oral MaxillofacSurg 1996;54:8537.

3. International Agency for Research on Cancer. Globocan: 2008. Available from: http://www.globocan.iarc.fr/factsheet.asp. [Last accessed on 2014 Mar 03].
4. Reingold IM. Cutaneous metastases from internal carcinoma. Cancer 1966;19:162-8.

5. Gottlieb J, Schermer DR. Cutaneous metastasis from carcinoma of colon. JAMA 1970;213:2083.

6. Pak HY, Foster BA, Yakota SB. The significance of cutaneous metastasis from visceral tumors diagnosed by fine needle aspiration biopsy. Diagn Cytopathol. 1987;3:24-9.

7. Calhoun KH, Fulmer P, Weiss R, Hokanson JA. Distant metastases from head and neck squamous cell carcinomas. Laryngoscope 1994;104:1199-205.

8. Kumar N, Bera A, Kumar R, Ghoshal S, Angurana SL, Srinivasan R. Squamous Cell Carcinoma Of Supraglottic Larynx With Metastasis To All Five Distal Phalanges Of Left Hand. Indian Journal of Dermatology. 2011;56(5):578-580.

9. Krunic AL, Cockerell CJ, Truelson J, Taylor RS. Laryngeal squamous cell carcinoma with infradiafragmatic presentation of skin metastasis. ClinExpDermatol2006;31:242-4.

10. Bottoni U, Inocenzi $\mathrm{D}$, Mannooranparampic TJ, Richetta A, Del Guidice M, Calvieri S. Inflammatory cutaneous metastases from laryngeal carcinoma. Eur $\mathrm{J}$ Dermatol. 2001;11:124-6.

11. Looking bill DP, Spangler N, Helm KF. Cutaneous metastases in patients with metastatic carcinoma: A retrospective study of 4, 020 patients. J Am Acad Dermatol. 1993;29:228-36.

12. Calvieiri S, Chimenti S, Zampetti $M$, Bottoni U, Nini G, Ribuffo M. Metastases skin cancer visceral. Am ClinDermatol. 1980;34:349-56.

13. Weber FP. Bilateral thoracic zosteris spreading marginate telangiectatic probably a variety of carcinoma and better termed carcinoma telangectasicum. Br J Dermatol. 1933;45:418-24.

14. Innocenzi D, Bianchi L, Barduagni $\mathrm{O}$, Carlesimo PA $2^{\text {nd }}$. Carcinoma telangectasico of Parkes-Weber. Giorn It DermVener. 1988;123:19-24.

15. Dey A, Sinha RT. Cutaneous metastasis as an initial presentation of an unknown primary. Clin Cancer Investig J 2015;4:399401.

16. David O, Kluskens L, Reddy V, Gattuso P. Malignant cutaneous and subcutaneous abdominal wall lesions: a fine-needle 
aspiration study. DiagnCytopathol. 1998;19: 267-69.

17. Falagas ME, Vergidis PI. Narrative review: diseases that masquerade as infection cellulitis. Ann Intern Med. 2005;142(1):4755 .

18. L. K. Simpson, L. S. Ostlere, C. Harland. S. Gharaie. Treatment with carbon dioxide laser of painful skin metastases from a laryngeal neuroendocrine carcinoma. ClinExpDermatol. 2009 Dec;34(8):e873-5
19. Loredana ES, Rucsandra CD, Claudia C, Raluca NC, Otilia CR, Andreea-OE. Cutaneous metastases in squamous cell carcinoma of the larynx Case report. RoJCED 2015; 2(4):260-264

How to cite this article: Tele J, S.R. Kanetkar, S.S. Kumbhar et.al. Solitary cutaneous metastasis of carcinoma larynx - an unusual occurrence. Int J Health Sci Res. 2022; 12(2): 194-198. DOI: https://doi.org/10.52403/ijhsr. 20220227 